\title{
Chronic pleuritic pain in four patients with asbestos induced pleural fibrosis
}

\author{
A Miller
}

\begin{abstract}
Four patients occupationally exposed to asbestos, each suffering at least eight years of disabling, persistent, and often bilateral pleuritic pain are described. Radiographic evidence of pleural disease ranged from plaques seen only on computed tomography to typical bilateral plaques or diffuse thickening to extensive diffuse and circumscribed pleural fibrosis and calcification. There was no history or evidence of acute pleuritis or pleural effusion in three patients. Intermittent pleural friction rubs have been present in all four; one patient showed pleural uptake of gallium-67. Extensive workups including repeated pulmonary ventilation-perfusion scans and cardiac catheterisation have not yielded other diagnoses to explain the pain. It is proposed that persistent pleuritic pain be added to the manifestations of benign asbestos induced pleural disease.
\end{abstract}

Two types of chronic asbestos induced pleural fibrosis are well described-namely, circumscribed (plaques) and diffuse, ${ }^{1}$ the latter generally a residual of inflammatory pleural effusions. ${ }^{23}$ Although intense inflammation may be evident on histological examination in asbestos induced chronic diffuse pleural fibrosis, ${ }^{4}$ clinical symptoms are not those of active inflammation. Pleuritic pain is notable by its absence. Indeed, unless experiencing recurrent effusions, patients are asymptomatic or notice shortness of breath attributable to ventilatory insufficiency $^{45}$ (or underlying asbestosis of the lung). The pleura seems to behave differently from the pericardium; chronic recurrent or persistent pain, or both, is a feature of many forms of pericarditis but is not seen in chronic pleuritis of diverse aetiologies.

In a practice that includes many patients with asbestos induced pleural fibrosis I have noted a few who complain of continuing chest pain or discomfort that is not clearly pleuritic. I have also encountered

Division of Pulmonary Medicine, Department of Medicine, Mount Sinai School of Medicine, Box 1232, New York, New York 10029, USA

A Miller four patients with documented benign asbestos induced pleural disease who have persistent pain of clearly pleuritic nature variably accompanied by other manifestations of pleural inflammation including friction rub and positive gallium scan.

\section{Case reports}

PATIENT 1 (date of birth 13 December 1919)

This man came to me in October 1979 because of persistent chest pain of several months duration. This pain varied in intensity, was left or right sided, or both, anterior or posterior, or both, but never relented completely and was exacerbated by inspiration, cough, and movement. He was dyspnoeic on climbing one and a half flights of steps.

He had experienced a right sided spontaneous pneumothorax on 4 April 1976 that required decompression with a pleural tube. After this he began to experience anterior pleuritic pain radiating to the shoulders. On 8 November 1976 he suffered a recurrence of the right pneumothorax which could not be expanded by pleural suction, and a thoracotomy was performed. Subpleural apical blebs measuring up to $0.5 \mathrm{~cm}$ in diameter were resected as a wedge and oversewn and the parietal pleura was stripped. Parietal pleura showed "a white, firm, plaque measuring $2 \times 1 \times 0.2 \mathrm{~cm}$." On microscopic examination the pleura showed "fibrosis and chronic inflammation"and the lung "patchy, marked interstitial fibrosis" (fig 1). No connection was made between this patient's occupational history (see below) and these findings of a typical asbestos pleural plaque and interstitial pulmonary fibrosis.

The chest pain continued, now associated with dyspnoea and friction rub. A diagnosis of pericarditis was entertained but not supported by electrocardiograms. The pain and the rub cleared with prednisone treatment but recurrent episodes of pain responded to prednisone less well and the localisation of the pain changed to that described above.

\section{Occupational history}

The patient had been an iron worker and boilermaker, beginning work at the first of several shipyards in 1938. He had to remove asbestos insulation from ceilings, walls, and pipes and he mixed asbestos cements used on boilers. In 1952 a 
Figure 1 Resected lung tissue from patient 1 (haematoxylin and eosin stain) showing alveolar septal fibrosis and likely ferruginous body.

17 metre fall aboard ship left him comatose for three weeks, fractured his right arm and leg, and detached a retina. He then stopped smoking his one pack of cigarettes a day. After seven years of rehabilitation, he returned to work as an inspector of rolling stock for the New York City subways, working as such for the next ten years without exposure to asbestos. He was placed on light duty in 1979 but could not continue working in 1980 because of the pleuritic pain and dyspnoea.

On examination he was a chronically ill white man who appeared to be his stated age of 59 and had obvious chest pain. This was exacerbated by deep breath, cough, and movement of his torso or arms. Right thoracotomy and anterior thoracotomy scars were present, as were fine inspiratory basal rales. There was no finger clubbing.

Chest radiographs from 1979 to 1986 showed only blunting of the right costophrenic angle (attributable to his thoracotomy) and a calcific plaque over the right upper lobe coded as Al on the ILO scale. The parenchyma was normal $(0 / 0)$ as were the heart and hila.

The histological slides from his wedge resection were now sent to the Mount Sinai School of Medicine. Dr Yasunosuke Suzuki reported "advanced pulmonary asbestosis" with interstitial fibrosis and calcification and associated calcific pleural plaque. There were many ferruginous bodies, free or within macrophages, both intra-alveolar and interstitial.

It was apparent that asbestosis could explain his progressive dyspnoea and rales, despite the paucity of radiographic findings, and it seemed possible that an active asbestos induced pleuritis might explain his chronic pleuritic pain and intermittent friction rub.

After failure of a wide variety of analgesics and non-steroidal anti-inflammatory agents to bring relief, the patient was admitted to the Mount Sinai School of Medicine in January 1980 for further evaluation. Haematological and chemical profiles, erythrocyte sedimentation rate, antinuclear antibody studies, and latex fixation were normal. Two gallium scans were made over a ten day interval and showed persistent uptake in both apices, hila and bases, read as "pleural localisation, rule out mesothelioma." The mitral and aortic valves were normal on echocardiography. On right heart catheterisation, all pressures were normal, cardiac output was $6 \mathrm{l} / \mathrm{min}$ and there was no evidence of pericardial constriction. Computed tomography of the chest showed multiple sites of pleural thickening (more on the left) that did not correlate with the areas of gallium uptake and questionable evidence of interstitial fibrosis. 
Complete pulmonary function tests showed only a slight decrease in diffusing capacity $(6.89 \mathrm{mmol} / \mathrm{min} /$ $\mathrm{kPa}$ or $20.6 \mathrm{ml} / \mathrm{min} / \mathrm{mm} \mathrm{Hg}, 69 \%$ of predicted ${ }^{6}$ ) and an increase in physiological dead space $\left(\mathrm{V}_{\mathrm{D}} / \mathrm{V}_{\mathrm{T}} 0 \cdot 49\right)$ at rest. For consistency, the same predictive equations have been used for all studies on all patients, even if they had not been published when the tests were performed. Full lung volumes by plethysmography, spirometry (including $\mathrm{FEF}_{25-75^{\prime \prime} \text { ), }}$ maximum voluntary ventilation, and dynamic compliance at basal respiratory rate were normal; the vital capacity was 4.401 ( $83 \%$ of predicted). ${ }^{7}$

The $\mathrm{PaO}_{2}$ varied from 71 to $77 \mathrm{~mm} \mathrm{Hg}$ at rest (minimally reduced), did not fall with two minutes of step up exercise, and rose appropriately on inhalation of $100 \% \mathrm{O}_{2}$. Small airways disease was suggested by

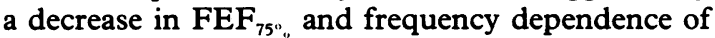
compliance. The increase in dead space ventilation and slight decrease in diffusing capacity were consistent with interstitial lung disease, despite the normal lung volumes and compliance and the absence of radiographic findings.

The evaluation during this period in hospital confirmed both bilateral pleural plaque formation not apparent on conventional radiography and an active pleural inflammation capable of taking up Ga-67 citrate. The chest pains could not be attributed to mitral valve prolapse or pericarditis. Evidence of interstitial lung disease from the pulmonary function and radiographic studies was less striking than from the histological lesions.

The course over the next six years has not changed. The pains, variably associated with a pleural rub, have never abated and on several occasions were so severe on one side or the other as to bring him to various hospital emergency rooms to rule out pneumothorax or pulmonary embolism. Repeated attempts to relieve the pain with non-steroidal antiinflammatory drugs and steroids have been unsuccessful. Dyspnoea has persisted. He was readmitted to the Mount Sinai Hospital in October 1982 because of these symptoms and blood streaking. Fibreoptic bronchoscopy showed no endobronchial lesions; transbronchial biopsy showed interstitial fibrosis and ferruginous bodies. The FVC and TLC were lower, $3.881(67 \%$ of predicted) and $5.611(68 \%$ of predicted), respectively, whereas the $\mathrm{D}_{\mathrm{L}} \mathrm{CO}_{\mathrm{SB}}$ was unchanged $(6.35 \mathrm{mmol} / \mathrm{min} / \mathrm{kPa} ; 19.0 \mathrm{ml} / \mathrm{min} / \mathrm{mm}$ $\mathrm{Hg}$ ).

On physiological re-evaluation in February 1987, the FVC was 3.401 (decreased from 1982), $\mathrm{FEV}_{1}$ $2 \cdot 82 \mathrm{l}, \mathrm{FEV}_{1} / \mathrm{FVC}^{0} \cdot 83, \mathrm{FEF}_{25-75{ }^{\circ}} 2.98 \mathrm{l} / \mathrm{sec}(93 \%$ of predicted), ${ }^{7}$ but the $\mathrm{D}_{\mathrm{L}} \mathrm{CO}_{\mathrm{SB}}$ was now $4.62 \mathrm{mmol} /$ $\mathrm{min} / \mathrm{kPa}(13.8 \mathrm{ml} / \mathrm{min} / \mathrm{mm} \mathrm{Hg}), 49 \%$ of predicted. ${ }^{6}$ Results on incremental exercise testing were: maximum $\mathrm{O}_{2}$ consumption $1.19 \mathrm{l} / \mathrm{min}$ ( $51 \%$ of predicted), maximum ventilation $881 / \mathrm{min}\left(78 \%\right.$ of predicted), ${ }^{8}$ normal heart rate response, considerably increased ventilatory response, excessive dead space ventilation without the expected fall on exercise $\left(V_{D} / V_{T} 0.47\right.$ at rest and 0.45 at $\mathrm{VO}_{2} 1.0 \mathrm{l}$ ), and slight exercise induced hypoxaemia $\left(\mathrm{PaO}_{2} 69 \mathrm{~mm} \mathrm{Hg}\right.$, alveolar arterial difference $40 \mathrm{~mm} \mathrm{Hg}$ ). These abnormalities are characteristic of interstitial fibrosis.

PATIENT 2 (date of birth 19 June 1932)

This man was seen in October 1988. He began experiencing chest pains in 1981 . He was admitted to hospital in 1982 with severe chest pain to "rule out pulmonary infarction" and was discharged taking muscle relaxants. He has continued to experience bilateral, primarily right sided, anterior chest pain increasing with cough, deep breathing, sneeze, straining, and certain motions. Cardiac catheterisation in 1986 was normal. He is dyspnoeic on walking one block rapidly.

Past history includes allergic rhinitis (with negative sinus films) treated by immunotherapy, upper gastrointestinal haemorrhage in 1986, and chronic back syndrome but no pleurisy or pneumonia. He has never smoked.

\section{Occupational history}

The patient was exposed to asbestos insulation as a bystander from 1951 to 1954 and as a maintenance mechanic in nylon and mylar plants, removing old insulation, cutting asbestos blocks, and mixing and applying asbestos cements from 1954 to 1981 .

On examination, the patient changed position with obvious pain in the right chest that increased on deep breathing. A pleural friction rub was heard on the right, greater anteriorally.

The ECG was normal but chest radiographs in 1988 showed bilateral calcified diaphragmatic plaques and calcified chest wall plaques coded as $R B$, 1 en face 2 and $L$ en face 2 (fig 2 ). The parenchyma was normal except for a small area of atelectasis in the left costophrenic angle. The earliest film in 1969 showed a left diaphragmatic plaque and right chest wall plaque A1. Computed tomography in 1982 showed only pleural thickening.

Pulmonary function results were available from 1979 to 1988. Spirometric efforts were associated with chest pain. The FVC decreased gradually from 5.621 in 1979 to 4.391 in 1986 and more steeply to $3.081(61 \% \text { of predicted })^{7}$ in 1988 , with corresponding FEV 1 values $3.76 \mathrm{l}, 3.19 \mathrm{l}$, and $2.441(61 \%$ of predicted) and $\mathrm{FEV}_{1} / \mathrm{FVC}$ ratios $0 \cdot 67,0 \cdot 65$, and $0 \cdot 79$. The FRC, RV, TLC, and $\mathrm{D}_{\mathrm{L}} \mathrm{CO}_{\mathrm{SB}}$ have been normal. The maximum voluntary ventilation in 1988 was borderline, $87 \mathrm{l} / \mathrm{min}, 79 \%$ of predicted. ${ }^{8}$ These results are consistent with a progressive restrictive impairment of chest cage type; earlier evidence of slight airways obstruction is no longer detectable.

The chest pains have persisted despite treatment 
Chest radiographs, posteroanterior, patient 2, (A), made in 1988, shows bilateral diaphragmatic and chest wall plaques which have progressed since (B), made in 1976.

with analgesics, anti-inflammatory agents, anxiolytics, and muscle relaxants. Although he was assigned to light duty, he had to stop working early in 1988 and no longer engages in previous activities, such as fishing or lawn mowing. Psychiatric and psychological (Minnesota multiphasic personality inventory) evaluations yielded a diagnosis of "psychologic factors (either depressive disorder or adjustment disorder with mixed anxiety and depression) contributing to a physical condition-chronic pain (DSM-III-R316.0)." Hypochondriacal neuroses, conversion disorder, and malingering were not thought to be present.

\section{PATIENT 3 (date of birth 21 August 1909)}

This man was referred by a cardiologist in September 1987 for left and, less frequently, right anterior pleuritic pain over the past ten years. The pain had at first come on once a week but was now present each day, lasting all day. The pain was increased by a deep breath and by movement and was neither exertional nor radiating. It was difficult to evaluate dyspnoea because of limited activity due to pain.

Past history included a myocardial infarction in 1974, aortic stenosis, and single vessel coronary disease confirmed at cardiac catheterisation in 1982 and an episode of congestive heart failure in September 1986, which included new bilateral pleural effusions and peripheral oedema responding to diuretic treatment. On gated blood pool scan, the left ventricle was enlarged and hypokinetic, with dyskinesia of the apex consistent with a large apical

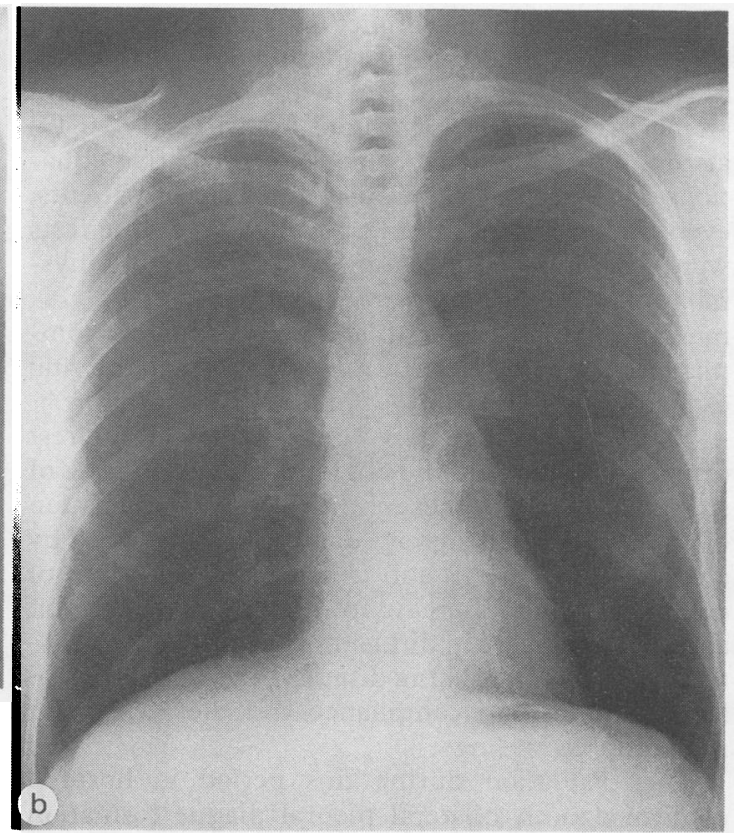

aneurysm. The ejection fraction was $26 \%$. The patient had smoked one pack of cigarettes a day but switched to a pipe in 1962 and discontinued all tobacco in 1986.

\section{Occupational history}

He was a plumber's helper (1925-9) and then a plumber (1929-41, 1945-72), occasionally mixing and applying asbestos cements, installing pipes around asbestos insulated boilers, and working alongside insulators. From 1940 to 1945 , he was a pipefitter foreman at several shipyards and power plants, working in boiler rooms and frequently removing asbestos insulation.

On examination, chest expansion was normal; pleural rubs were heard anteriorally on both sides. A grade $3 / 6$ systolic "sea gull" murmur at the apex radiated to the left axilla and a grade $3 / 6$ systolic murmur at the aortic area radiated to the neck. Finger clubbing was not present. The ECG showed an old anteroseptal infarct, left anterior hemiblock, and premature atrial and ventricular beats.

Chest radiographs showed extensive bilateral calcific pleural thickening, both diffuse and circumscribed (RC3, en face $2, \mathrm{~L} \mathrm{C2}$, en face 3), with blunting of both costophrenic angles and calcification of both diaphragms and the left mediastinal pleura (fig 3). As well as could be discerned, the lung fields were $s / t, 0 / 1$, and the heart was not enlarged. Computed tomography confirmed the pleural abnormalities described above and the normal cardiac 


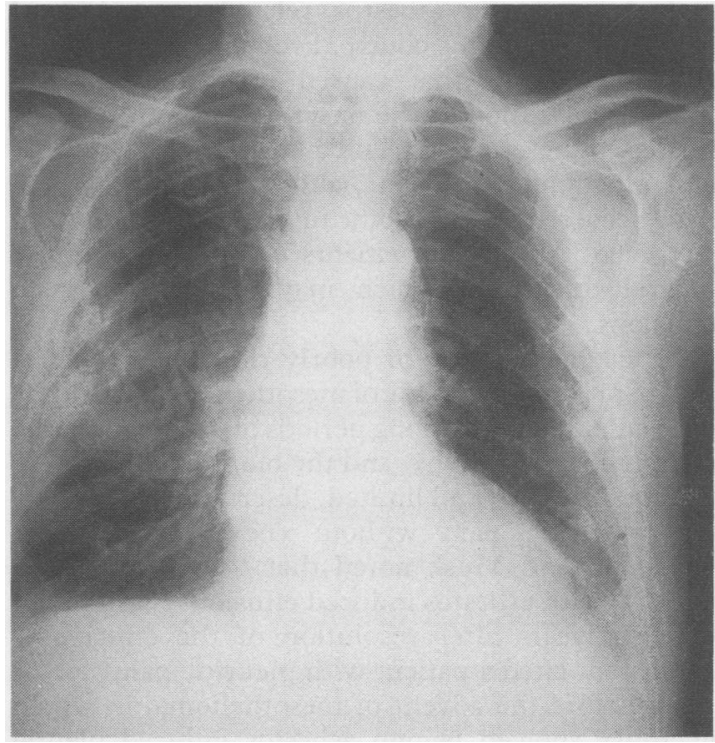

Figure 3 Chest radiograph, posteroanterior, patient 3, showing extensive bilateral calcified pleural thickening of the chest wall, diaphragm, and mediastinum.

contours and absence of interstitial fibrosis. Gallium scan was technically unacceptable.

On spirometric testing, the VC was $2.361(77 \%$ of predicted), $\mathrm{FEV}_{1} 2.251$ ( $94 \%$ of predicted), $\mathrm{FEV}_{1} /$ FVC $0.95, \mathrm{FEF}_{25-75 " .} 3.081 / \mathrm{sec}(131 \% \text { of predicted })^{7}$ and maximum voluntary ventilation $69 \mathrm{l} / \mathrm{min}\left(75^{\circ} \%\right.$ of predicted). ${ }^{8}$ The vital capacity was unchanged from values a year earlier, at which time the $\left(\mathrm{N}_{2}\right.$ washout) functional residual capacity was 3.121 $(103 \%$ of predicted), the residual volume 2.251 (104\% of predicted), and total lung capacity 4.43 ( $92 \%$ of predicted). ${ }^{9}$ Results suggested a minimal restrictive impairment.

The patient was advised to continue his diltiazem and diuretic regimen. Manipulating the route, schedule, and dosage of nitrate treatment did not affect his pleuritic pain. Repeated attempts to ameliorate the pain with aspirin, various nonsteroidal agents, and prednisone were unsuccessful.

PATIENT 4 (date of birth 4 October 1940)

He was first reviewed at Mount Sinai Hospital on 21 June 1982. He had been admitted to St Thomas Hospital, Nashville, Tennessee, in April 1978 for chills and dyspnoea that had begun one month earlier. He was treated with antibiotics and steroids and was admitted to hospital again five months later for persistence of these symptoms. Fibreoptic bronchoscopy including biopsy was normal. Adhesions were noted on open pleural biopsy; histological examination showed fibrous tissue with infiltration of mature lymphocytes around small blood vessels. Because of a positive tuberculin test (second strength), the patient was treated with isoniazid which was discontinued after three weeks because of hepatitis.

In March 1979 the patient noted left pleuritic pain, fever, malaise, and dyspnoea, with a rub on physical examination and a large left pleural effusion. The fluid was exudative; pleural biopsy showed fibrosis with "dense infiltration of histiocytes, lymphocytes, and eosinophils" and mesothelial proliferation. After three thoracenteses, fluid was no longer present but pleuritic pain, rubs, and fluid reappeared within two weeks, requiring a chest tube. A third pleural biopsy showed similar findings. Results of bacterial, viral, fungal, and mycobacterial cultures and stains were negative and right and left sided pleural effusions caused by asbestos were diagnosed.

\section{Occupational history}

The patient had been an asbestos insulator since 1963 (at age 23), working in constructing power plants and removing old insulation.

$\mathrm{He}$ could return to work despite the persistent exertional dyspnoea, right pleuritic pain requiring codeine, chills, and fever. Pleural friction rubs were heard throughout this period. On review at the Mount Sinai Hospital, chest radiographs from 1980 to 1982 showed bilateral diffuse pleural thickening (A 2, face on 1), and irregular small opacities coded as $1 / 1$.

Because of the persistent pain of the right chest, xylocaine was injected into the chest wall on several occasions, and in February 1984 intercostal nerve blocks were performed. Pain was unrelieved and in April 1984 the right intercostal nerves were surgically interrupted. On this admission, breath sounds and resonance were diminished at the right base and a rub was present.

The stabbing pleuritic component of the patient's chest pain was no longer present; he discontinued pain medication and gained weight. Bronchoscopy was performed on 28 February 1986 because of haemoptysis. Biopsy showed chronic bronchitis, denuded mucosa, and goblet cell hyperplasia; lung parenchyma showed numerous macrophages and "mild interstitial fibrosis."

By October 1986, however, the pain had increased in severity, was unresponsive to transcutaneous electrical nerve stimulation (TENS), and required narcotics. On 3 November 1986, the patient underwent $T_{3}-T_{9}$ laminectomy, right $T_{5-11}$ ganglionectomies, and DREZ lesioning of the $T_{5-11}$ dorsal root entry zones at Vanderbilt University Hospital in Nashville. Pain in the distribution of the 12th intercostal nerve persisted and was relieved only with a block of this nerve; ganglionectomy was then performed. Pain persists above $T_{5}$ and pain and 
muscle spasm below $T_{12}$. Nevertheless, the patient continues to work as a union official. He has been unable to stop smoking his usual daily pack of cigarettes.

Pulmonary function test results are available from 1978 to 1988 , showing little change in lung volumes but significant decrease in $\mathrm{D}_{\mathrm{L}} \mathrm{CO}_{\mathrm{SB}}$ during this ten year span: FVC $4.0(1978)$ to $3.501(1988 ; 65 \%$ of predicted), $\mathrm{FEV}_{1} 3.18$ to 2.661 (61 ${ }^{\circ}$ of predicted), $\mathrm{FEV}_{1} / \mathrm{FVC} 0.79$ to $0.76, \mathrm{FEF}_{25-75 \text { ". }} 3.46$ to $2.72 \mathrm{l} / \mathrm{sec}$ (72 ${ }^{\circ}$ of predicted), ${ }^{7}$ TLC 5.87 to $6.021(84 \%$ of predicted), RV 2.62 to 2.521 ( $110^{\circ}$ o of predicted), ${ }^{9}$ $\mathrm{PaO}_{2} 96$ to 97 Torr and $\mathrm{D}_{\mathrm{L}} \mathrm{CO}_{\mathrm{SB}} 8.76 \mathrm{mmol} / \mathrm{min} / \mathrm{kPa}$ $(26.2 \mathrm{ml} / \mathrm{min} / \mathrm{mm} \mathrm{Hg})$ to $5.85 \mathrm{mmol} / \mathrm{min} / \mathrm{kPa}(17.5$ $\mathrm{ml} / \mathrm{min} / \mathrm{mm} \mathrm{Hg}, 54^{\circ}$ of predicted). These results are consistent with a moderate restrictive impairment with loss of diffusing capacity.

\section{Discussion}

These four patients have in common their occupational exposure to asbestos, unequivocal evidence of asbestos related disease, and persistent, often bilateral, pleuritic pain. They are unlike in how they manifest their asbestos related disease clinically, in that patient 1 has no specific evidence of pleural or parenchymal disease on plain films (despite striking histological abnormalities of both tissues), patient 2 has typical pleural plaques, patient 4 typical diffuse thickening and small irregular opacities, whereas patient 3 has extensive diffuse and circumscribed pleural disease. Thorough physiological evaluation in patients 1 and 4 showed gas exchange abnormalities of interstitial fibrosis; all have slight to moderate restrictive impairment.

Other causes for chest pain in the three patients without a history of acute pleuritis or effusion have repeatedly been ruled out during the long periods they have been under observation. The first patient's two episodes of spontaneous pneumothorax (and subsequent surgical intervention), both on the same side, do not explain the bilateral manifestations, nor do consequences of his injuries 24 years before the onset of pain. Similarly, the heart disease shown in patient 3 does not explain his progressive pleuritic pain. All three patients have undergone cardiac catheterisation, coronary angiography, and repeated pulmonary ventilation perfusion scans.

No explanation can be offered for the persistence of the pleuritic pain in these four patients. Such pain has not been described in the many patients who have come to medical attention with asbestos induced pleural plaques or, indeed, in those with diffuse pleural fibrosis and calcification of asbestos induced, tuberculous, traumatic, or pyogenic aetiology. Recurrent, often bilateral, pleuritic pain has been described in acute asbestos induced pleurisy, in association with exudative effusions..$^{2310-13}$ Patient 4 had characteristic asbestos related acute pleural $\stackrel{2}{\vec{\Rightarrow}}$ effusions early in his course. Probably patient 3 had $\stackrel{5}{\rightarrow}$ similar effusions that caused his diffuse pleuralo thickening, although the onset of his pain was not 음 related to these. There is no evidence that patients $1 \frac{\bar{c}}{\frac{\rho}{\sigma}}$ and 2 had such effusions, although they may well $\stackrel{\Phi}{\varrho}$ have occurred and not come to medical attention. In any event, these two patients do not have diffuse $\rightarrow$ pleural thickening which may result from such $\vec{\circ}$ effusions.

Persistent pleuritic or poorly characterised chest $\stackrel{\omega}{\circ}$ wall pain is characteristic of mesothelioma, which has been ruled out by the long periods of observation, the $\vec{F}$ computed tomography, and the biopsies.

There are few, and limited, descriptions of persis- $\dot{\omega}$ tent pleuritic pain without coexisting effusion. $\vec{A}$ Robinson and Musk noted that three of their $22 \vec{\nabla}$ patients with asbestos induced effusions had pain up to eight years after resolution of the effusions. ${ }^{14} \rightarrow$ Eisenstadt cited a patient with pleuritic pains for $12 \frac{3}{2}$ years before the advent of mesothelioma, in whom necropsy showed benign asbestos induced pleural disease in those portions of the thorax not affected by $\mathscr{\Theta}$ the malignancy. ${ }^{10}$ Quite reasonably, he concluded. that "these pains must have been caused by a benign process preceding the malignancy."

Gaensler and Kaplan noted that asbestos induced pleural effusions may be "followed by continued $\cong$ chest pain," and cited several cases in which pain $\stackrel{\square}{\unrhd}$ persisted in the absence of effusions, in one case $\overrightarrow{\vec{A}}$ despite repeated intercostal nerve blocks and "resec- ำ tion of the costal arch." 3

There have been few reports of gallium scans in benign asbestos pleural disease. Teirstein and colleagues noted that three of 16 patients had positive $\overparen{\mathbb{D}}$ scans; these had exuberant diffuse pleuritis. ${ }^{15}$ The positive scans and intermittent rubs in patient 1 who has only plaques on computed tomography and bland histology on biopsy, the occasional rubs in patient 2 , 의 and the persistent rubs in patient 4 suggest that inflammatory activity may be present despite quiescent features.

The sequelae of benign asbestos induced pleural disease include recurrent exudative pleural effusion $N$ as well as minor ${ }^{16-18}$ and occasionally major ${ }^{45}$ impair- N ments of ventilatory function. A rare syndrome of $N$ persistent pleuritic pain that may be associated with $\stackrel{\omega}{O}$ other markers of active inflammation such as friction rubs and uptake of 67-gallium should be added to this list.

I thank my colleagues in the division of environ- $\stackrel{\mathbb{Q}}{\varrho}$ mental and occupational medicine, Drs Stephen $M \underset{\nabla}{\sigma}$ Levin and Steven B Markowitz, for referring patient 8 3 and providing their material on patient 4 . 
1 International classification of radiographs of pneumoconioses. Geneva: International Labour Office, 1980.

2 Epler GR, McLoud TC, Gaensler EA. Prevalence and incidence of benign asbestos pleural effusion in a working population. JAMA 1982;247:617-22.

3 Gaensler EA, Kaplan AI. Asbestos pleural effusion. Ann Intern Med 1971;74:178-91.

4 Miller A, Teirstein AS, Selikoff IJ. Ventilatory failure due to asbestos pleurisy. Am J Med 1983;75:911-9.

5 McGavin CR, Sheers G. Diffuse pleural thickening in asbestos workers: disability and lung function abnormalities. Thorax 1984;39:604-7.

6 Miller A, Thornton JC, Warshaw R, Anderson HA, Teirstein AS, Selikoff IJ. Single breath diffusing capacity in a representative sample of the population of Michigan, a large industrial state. Predicted values, lower limits of normal and frequencies of abnormality by smoking history. Am Rev Respir Dis 1983;127:270-7.

7 Miller A, Thornton JC, Warshaw R, Bernstein J, Selikoff IJ Teirstein AS. Mean and instantaneous expiratory flows, FVC and $\mathrm{FEV}_{1}$ : prediction equations from a probability sample of Michigan, a large industrial state. Bull Eur Physiopathol Respir 1986;22:589-97.

8 Bass H. The flow volume loop: normal standards and abnormalities in chronic obstructive pulmonary disease. Chest 1973;63:171-6.

9 Goldman HI, Becklake MR. Respiratory function tests. Normal values at median altitudes and the prediction of normal results. Am Rev Respir Dis 1959;79:457-67.

10 Eisenstadt HB. Asbestos pleurisy. Dis Chest 1964;46:78-81.

11 Eisenstadt HB. Benign asbestos pleurisy. JAMA 1965;192: 419-21.

12 Mattson S-B. Monosymptomatic exudative pleurisy in persons exposed to asbestos dust. Scand J Respir Dis 1975;56:263-72.

13 Chahinian P, Hirsch A, Bignon J. Les pleurisies asbestosiques non tumorales. Revue Francaise des Maladies Respiratoires 1973;1:5-39.

14 Robinson BWS, Musk AW. Benign asbestos pleural effusion: diagnosis and course. Thorax 1981;36:896-900.

15 Teirstein AS, Chahinian P, Goldsmith SJ, Sorek M. Gallium scanning in differentiating malignant from benign asbestosrelated pleural disease. Am J Ind Med 1986;9:487-94.

16 Becklake MR, Fournier-Massey G, McDonald JC, Shemiatycki $\mathrm{J}$, Rossiter CE. Lung function in relation to chest radiographic changes in Quebec asbestos workers. Bull Physiopathol Respir 1970;6:637-59.

17 Zitting A, Huuskonen MS, Alanko I, Mattson T. Radiographic and physiologic findings in patients with asbestosis. Scand $J$ Work Environ Health 1978;4:275-83.

18 Jarvholm B, Sanden A. Pleural plaques and respiratory function. Am J Ind Med 1986;10:419-26.

Accepted 14 August 1989

\section{Vancouver style}

All manuscripts submitted to the $B r J$ Ind Med should conform to the uniform requirements for manuscripts submitted to biomedical journals (known as the Vancouver style)

The $\mathrm{Br} J$ Ind Med, together with many other international biomedical journals, has agreed to accept articles prepared in accordance with the Vancouver style. The style (described in full in $\mathrm{Br}$ Med J, 24 February 1979, p 532) is intended to standardise requirements for authors.

References should be numbered consecutively in the order in which they are first mentioned in the text by Arabic numerals above the line on each occasion the reference is cited (Manson ${ }^{1}$ confirmed other reports ${ }^{2-5} \ldots$.). In future references to papers submitted to the BrJ Ind Med should include: the names of all authors if there are six or less or, if there are more, the first three followed by et al; the title of journal articles or book chapters; the titles of journals abbreviated according to the style of Index Medicus; and the first and final page numbers of the article or chapter.

Examples of common forms of references are:

1 International Steering Committee of Medical Editors. Uniform requirements for manuscripts submitted to biomedical journals. Br Med J 1979:1:532-5.

2 Soter NA, Wasserman SI, Austen KF. Cold urticaria: release into the circulation of histamine and eosino-phil chemotactic factor of anaphylaxis during cold challenge. $N$ Engl $J$ Med 1976;294:687-90.

3 Weinstein L, Swartz MN. Pathogenic properties of invading micro-organisms. In: Sodeman WA Jr. Sodeman WA, eds. Pathologic physiology: mechanisms of disease. Philadelphia: W B Saunders. 1974:457-72. 